\title{
Article
}

\section{Client and clinical staff perceptions of barriers to and enablers of the uptake and delivery of behavioural interventions for urinary incontinence: qualitative evidence synthesis}

French, Beverley, Thomas, Lois Helene, McAdam, Joanna, Coupe, Jacqueline, Roe, Brenda, Booth, Joanne, Cheater, Francine, Leathley, Michael John, Watkins, Caroline Leigh and Hay-Smith, Jean

Available at http://clok.uclan.ac.uk/14041/

French, Beverley, Thomas, Lois Helene ORCID: 0000-0001-5218-6546, McAdam, Joanna ORCID: 0000-0001-8963-7240, Coupe, Jacqueline, Roe, Brenda, Booth, Joanne, Cheater, Francine, Leathley, Michael John, Watkins, Caroline Leigh ORCID: 0000-0002-9403-3772 et al (2017) Client and clinical staff perceptions of barriers to and enablers of the uptake and delivery of behavioural interventions for urinary incontinence: qualitative evidence synthesis. Journal Of Advanced Nursing, 73 (1). pp. 21-38. ISSN 0309-2402

It is advisable to refer to the publisher's version if you intend to cite from the work. http://dx.doi.org/10.1111/jan.13083

For more information about UCLan's research in this area go to http://www.uclan.ac.uk/researchgroups/ and search for <name of research Group>.

For information about Research generally at UCLan please go to http://www.uclan.ac.uk/research/

All outputs in CLoK are protected by Intellectual Property Rights law, including Copyright law. Copyright, IPR and Moral Rights for the works on this site are retained by the individual authors and/or other copyright owners. Terms and conditions for use of this material are defined in the policies page. 


\section{TITLE PAGE}

Full title: Client and clinical staff perceptions of barriers to and enablers of the uptake and delivery of behavioural interventions for urinary incontinence: a systematic narrative review.

Running head: behavioural interventions for urinary incontinence: systematic narrative review.

\section{Author details:}

Beverley FRENCH, Reader in Evidence Based Healthcare (retired), School of Health, University of Central Lancashire, Preston, UK. PhD RN

Lois H THOMAS, Reader in Health Services Research, School of Health, University of Central Lancashire, Preston, UK. PhD BA (Hons) RN

Joanna MCADAM NIHR CLAHRC NWC Research Capacity Delivery Manager, School of Health, University of Central Lancashire, Preston, UK. MA BA (Hons)

Jacqueline COUPE Research Associate, School of Health, University of Central Lancashire, Preston, UK. MPH BSc (Hons) MBPsS

Brenda ROE, Professor of Health Research, Evidence Based Practice Research Centre, Edge Hill University, Ormskirk, UK. PhD RN RHV

Joanne BOOTH Professor of Rehabilitation Nursing, Department of Nursing \& Community Health, School of Health \& Life Sciences, Glasgow Caledonian University, Glasgow, UK. PhD, BSc (Hons), BA, RN

Francine CHEATER Professor of Public Health \& Implementation Science, School of Health Sciences, University of East Anglia, Norwich, UK. PhD BA (Hons) RN

Michael J LEATHLEY Principal Lecturer, School of Health, University of Central Lancashire, Preston, UK. PhD BA (Hons) PGDip

Caroline L WATKINS Professor of Stroke and Older People's Care, School of Health, University of Central Lancashire, Preston, UK and Professorial Fellow in Stroke Care, Faculty of Health Sciences, Australian Catholic University, Sydney, Australia. PhD BA (Hons) RN

Jean HAY-SMITH Associate Professor, Rehabilitation Teaching and Research Unit, Department of Medicine, University of Otago, Wellington, New Zealand; Department of Women's and Children's Health, Dunedin School of Medicine, University of Otago, Dunedin, New Zealand. PhD MSc DipPhysiotherapy MPNZ

On behalf of the ICONS Project Team and the ICONS Patient, Public and Carer Groups.

\section{Acknowledgements}

Funding for this study was provided by the UK National Institute for Health Research (NIHR) under its Programme Grants for Applied Research scheme (RP-PG-0707-10059). The views expressed herein are the views of the authors and do not necessarily represent the views of the National Institute for Health Research.

\section{Conflict of interest statement:}

No conflict of interest has been declared by the author(s). 


\section{Funding statement:}

This paper presents independent research funded by the National Institute for Health Research (NIHR) under its Programme Grants for Applied Research scheme (RP-PG-0707-10059). 


\section{Abstract}

Aim: To evaluate factors influencing uptake and delivery of behavioural interventions for urinary incontinence from the perspective of clients and clinical staff.

Background: Behavioural interventions are recommended as first-line therapy for the management of urinary incontinence. Barriers to and enablers of uptake and delivery of behavioural interventions have not been reviewed.

Design: Systematic narrative review.

Data sources: MEDLINE, EMBASE, CINAHL, PsychInfo, AMED (inception to May 2013); Proceedings of the International Continence Society (ICS) (2006-13).

Review methods: ENTREQ reporting guidelines were followed. Studies where data were collected from clients or staff about their experiences or perceptions of behavioural interventions were included. Two reviewers independently screened records on title and abstract. Full-text papers were obtained for records identified as potentially relevant by either reviewer. Two reviewers independently filtered all full-text papers for inclusion, extracted findings and critically appraised studies.

Results: Seven studies involving 200 participants identified clients' views. Findings identified from at least one study of moderate quality included increased fear of accidents and convenience of treatment. Factors enabling participation included realistic goals and gaining control.

Six studies involving 427 participants identified staff views. Findings identified from at least one study of moderate quality included staff education and perceptions of treatment effectiveness. Enabling factors included teamwork and experience of success.

Conclusion: There is little detailed exploration of clients' experiences of, and responses to, behavioural interventions. Evidence for staff relates predominantly to prompted voiding in longterm residential care. Studies of the uptake and delivery of other behavioural interventions in other settings are warranted. 


\section{Summary statement}

\section{Why is this review needed?}

- Behavioural interventions are recommended as first-line therapy for the management of urinary incontinence.

- The barriers to and enablers of uptake and delivery of behavioural interventions from the perspective of clients and clinical staff have not been reviewed.

\section{What are the key findings?}

- Clients' views of barriers to participation in behavioural interventions included increased fear of accidents and convenience of treatment.

- Client factors enabling participation in behavioural interventions included having realistic goals and expectations and gaining a sense of control.

- Staff views of barriers to adopting behavioural interventions included staff education and perceptions of treatment effectiveness. Staff factors enabling the adoption of behavioural interventions included teamwork and experience of success.

\section{How should the findings be used to influence policy/practice/research/education?}

- Further research exploring clients' experiences of, and responses to, behavioural interventions is warranted.

- Further research into staff experiences of delivering behavioural interventions in a range of settings is recommended.

- Findings from the review were used to inform delivery of the intervention in the ICONS: Identifying Continence OptioNs after Stroke randomised controlled feasibility trial.

Keywords: qualitative evidence synthesis, systematic review, urinary incontinence, management of incontinence, behavioural interventions, nursing, bladder training, prompted voiding, pelvic floor muscle training 


\section{INTRODUCTION}

Urinary incontinence (UI), defined as "involuntary loss of urine" (Abrams et al. 2002), is common in the general population and can affect people of all ages. More than one in three people over 40 years of age reported symptoms of bladder problems in a large survey by Perry et al. (2000), although most did not find their symptoms sufficiently bothersome to seek help.

$\mathrm{UI}$ following stroke is common, with prevalence estimates suggesting around half of stroke survivors are affected in the acute phase and findings similar across countries (Lawrence et al. 2001, Nakayama et al. 1997, Kolominsky-Rabas et al. 2003). As many as $43.5 \%$ and $38 \%$ stroke survivors remain incontinent at three months and one year respectively (Williams et al. 2012). In longer term stroke survivors (on average nine years post-stroke), prevalence has been reported as $17 \%$ (Jorgensen et al. 2005).

Damage to the pontine micturition centre or higher centres, particularly the medial aspects of the frontal lobes of the brain, can disrupt micturition pathways leading to impaired bladder storage and voiding (Panicker et al. 2010). Urge incontinence is the most common type after stroke (Pettersen et al. 2007) and is generally the result of detrusor overactivity (Arunabh \& Badlani 1993). Associated stroke impairments may compound difficulties with bladder control with motor, visual, mood or speech problems making the practical task of access (or requesting access) to toilet facilities a challenge (Brittain et al. 1999).

Problems with continence have been shown to be amenable to early intervention, particularly in the three months following stroke (Marinkovic \& Badlani 2001). Stroke outcome may be better in those stroke survivors who remain continent or regain continence (Barer 1989). While there are problems with attributing better stroke outcome to improvements in continence, it is possible early intervention aimed at promoting recovery from incontinence may improve morale and self-esteem and therefore speed overall stroke recovery (Barer 1989, Patel et al. 2001). It is also possible that the recovery of continence reduces barriers to participation in rehabilitation activity.

In this paper we report findings from a qualitative evidence synthesis which aimed to identify barriers to and enablers of the successful uptake and delivery of behavioural interventions from the perspective of clients and clinical staff. The review formed part of the ICONS: Identifying Continence OptioNs after Stroke Programme Grant for Applied Research funded by the National Institute for Health Research (Thomas et al. 2015). The programme was structured in line with the Medical Research Council (MRC) framework for the evaluation of complex interventions (Medical Research Council, 2000; Medical Research Council, 2008); this review was undertaken as part of the MRC development phase and updated in 2013. 


\section{Background}

Despite the availability of clinical guidelines for the management of $\mathrm{UI}$ in women (National Collaborating Centre for Women's and Children's Health 2013) and after stroke (Intercollegiate Stroke Working Party 2012), national audit data suggest incontinence is often poorly managed. In the latest Sentinel Stroke National Audit Programme (SSNAP)[Royal College of Physicians 2014], 17\% of incontinent patients did not have a plan for continence management within three weeks of arrival on the stroke unit, a statistic described by the authors as "terrible".

While continence is already recognised as a component of organised stroke care, it is known that nurses find managing continence in the context of stroke challenging (Booth et al. 2009), with overreliance on urinary catheterisation as a management strategy especially in the acute phase of illness Cowey et al. 2012). There are medical therapies (e.g. antimuscarinic medications such as Oxybutinin; posterior tibial nerve stimulation) which can be appropriately used to assist continence but these need to be based on appropriate first line assessment and behavioural management in line with national guidelines (Intercollegiate Stroke Working Party 2012).

Behavioural interventions are recommended as first-line therapy for the management of UI (Intercollegiate Stroke Working Party, 2012; National Institute for Health and Care Excellence, 2012). These include bladder training (Wallace et al. 2004), timed voiding (Ostaszkiewicz et al. 2004b), prompted voiding (Eustice et al. 2000), habit retraining (Ostaszkiewicz et al. 2004a) and pelvic floor muscle training (Dumoulin et al. 2014).

The effectiveness of behavioural interventions has been systematically reviewed in adults. The review of timed voiding (Ostaszkiewicz et al. 2004b) included only two trials of poor methodological quality and concluded there was no empirical evidence for or against the intervention. Similarly, the review of habit retraining (Ostaszkiewicz et al. 2004a) found insufficient evidence of an effect on continence outcomes to recommend this approach. In the review of bladder training (Wallace et al. 2004), trials tended to favour bladder training and there was no evidence of adverse effects. The review of prompted voiding (Eustice et al. 2000) found evidence of increased self-initiated voiding and decreased incontinent episodes in the short-term. Pelvic floor muscle training may also be effective in assisting the individual to manage urge, stress or mixed incontinence (Dumoulin et al. 2014), and has been shown to be effective as a combined intervention with bladder training (Williams et al. 2005; Wyman et al. 1998). 
A meta-study of systematic reviews of behavioural interventions has called for clarity in the theory underpinning the use of behavioural interventions for urinary incontinence (Roe et al. 2007b; Roe et al. 2007a). In addition, the conditions and contexts for successful implementation of behavioural interventions for UI have not been reviewed.

\section{THE REVIEW}

\section{Aim}

To evaluate the evidence for factors influencing uptake and delivery of behavioural interventions for urinary incontinence in the general adult population from the perspective of clients and clinical staff to inform the design of an intervention specific to UI post-stroke.

\section{Design}

Systematic narrative review adhering to the ENTREQ reporting guidelines (Tong et al. 2012).

\section{Search methods}

The review included studies collecting data from adult clients or staff about their perceptions or experiences of behavioural interventions, including information on factors influencing:

- choice or uptake of behavioural interventions for UI

- adherence to/maintenance of a behavioural programme

- withdrawal/dropout from a behavioural programme

Studies exploring client experience of self-management strategies for $\mathrm{UI}$ in general were excluded if behavioural interventions were not referred to specifically. Studies were also excluded if the urinary incontinence related to a temporary condition such as pregnancy (UI within 12 months of childbirth was excluded), or a non-behavioural treatment such as surgery (e.g. prostatectomy).

Included study designs were qualitative studies and qualitative components of quantitative surveys.

The search strategy was pre-planned (rather than iterative) and drew on the search developed by the Cochrane Incontinence Review Group for terms related to urinary incontinence and from previous Cochrane reviews on behaviour change. These were combined, and then limited for exclusions related to age (non-adult), and language (non-English). The search was designed for MEDLINE (Appendix 1) and then adapted for other databases. We searched MEDLINE, EMBASE, 
CINAHL, PsychInfo, AMED from inception to May 2013, and Proceedings of the International Continence Society (ICS) (2006-13). We undertook forward and lateral citation searching via ISI Web of Knowledge for all included studies. The search strategy was developed to locate all relevant studies for the whole series of reviews for the ICONS Programme Grant (including a review of effectiveness) (Thomas et al. 2015).

\section{Search outcome}

The main database search identified 12,900 records (Figure 1). Another 47 records were added from conference proceedings, plus 72 records from secondary references. After removal of duplicates and clearly irrelevant titles, 3236 records were screened. Of these, 620 full text papers were retrieved. Five records could not be traced. Studies originally deemed eligible but subsequently excluded are detailed in Appendix 2. Thirteen studies were eligible for the review.

\section{Quality appraisal}

Quality assessment was based on quality criteria for qualitative studies or observational designs (Critical Appraisal Skills Programme, 2013) including criteria related to participant selection and representativeness, data collection and analysis, methods of representation and testing the robustness of findings. The National Institute for Health and Care Excellence (2007) quality classification was used as follows:

- studies where the credibility of the findings are unlikely to be affected by any weaknesses in study design or conduct (++);

- studies where weaknesses in study design or conduct have the potential to impact on the credibility of the findings (+);

- studies where the credibility of the findings is likely to be affected by weaknesses of study design or conduct (-).

\section{Data extraction}

After removal of duplicate records and records obviously not relevant to the review by one reviewer, two reviewers independently screened the remaining records on title and abstract. Full-text papers were obtained for screened records identified as potentially relevant by either reviewer. Two reviewers also independently filtered all full-text papers for inclusion, using a filtration pro-forma. 
Data extraction templates were designed with outcome formats and criteria for critical appraisal, together with coding frames and guidance. After training and inter-rater reliability checks for coding and quality assessment, critical appraisal and data extraction were undertaken independently by two reviewers. Disagreements were resolved through discussion; on no occasion was it necessary to consult a third reviewer.

Two reviewers (BF, LT) independently checked descriptive data, extracted findings and critically appraised the studies. Data were extracted on client group recruitment and inclusion criteria, research design and methods, behavioural intervention and findings.

\section{Synthesis}

Findings were identified from second order constructs, i.e. the study authors' aggregate themes, categories or codes relating to potential barriers to and enablers of behavioural interventions. Findings were categorised based on Davidson et al. (Davidson et al. 2003) and National Institute for Health and Care Excellence guidance on interventions to support behaviour change (National Institute for Health and Care Excellence, 2007). These included:

- intervention type (i.e. bladder training [BT], pelvic floor muscle training [PFMT], prompted voiding [PV]);

- influencing factor source: client, therapy or context;

- direction: barriers or enablers;

- outcome (choice/uptake, participation/adherence, longer-term sustainability, and withdrawal/drop-out).

We used a directed content analytic approach (Hsieh \& Shannon, 2005) drawing deductively on prespecified themes to classify the data and facilitate its presentation and synthesis. As the purpose of the review was to inform delivery of behavioural interventions in practice, analytical categories were imposed by us rather than being inherent in the original data, in contrast to the thematic approach developed by Thomas \& Harden (2008) where descriptive themes are generated from the data. Textual data were classified within the themes outlined above. Issues of classification and interpretation of the original data need to be taken into account when reading the synthesis, as does the inevitable loss of detail when summarising studies.

\section{Stakeholder involvement in the review process}


The ICONS Review Management Group met quarterly during the review process and their input included feasibility testing the data extraction proforma, checking back to the original study data from the results to comment on robustness of interpretation and reading and commenting on all review outputs. The ICONS Patient, Public and Carer Group were involved at three stages for consultation on the review: to advise on the parameters and scope of the review; to consider the draft results of the review in terms of identifying mediating factors for the feasibility trial; and to assist in the translation of the findings into practical guidance. The review findings were presented to the ICONS Trial Management and Steering groups who made suggestions for optimal conditions for delivery; these informed tailoring of the intervention to client groups and settings in the feasibility trial of combined behavioural interventions for the management of urinary incontinence after stroke in adults.

\section{RESULTS}

Findings relating to client and staff experience are reported separately.

\section{Description of studies of client experience}

Seven studies of client views or experiences were identified (summarised in Table 1). Two studies mainly referred to factors influencing choice/uptake of UI treatments in older people in residential care (Johnson et al. 2001; O'Dell et al. 2008). Three studies provided information about factors influencing participation and adherence to behavioural therapies (Milne \& Moore, 2006; Hay-Smith et al. 2007; Sarma et al. 2009), and two studies focused on reasons for drop-out from a UI treatment programme (Kincade et al. 1999; Maclnnes, 2008).

There were six qualitative studies, and one survey. All studies collected data from clients, but Johnson et al. (2001) used postal questionnaires to collect data from proxy respondents who did not themselves have urinary incontinence and also collected data from family members and nursing staff. The samples for two studies were designed to include both men and women (Johnson et al. 2001; Milne \& Moore, 2006), the rest included women only. Kincade et al. (1999) included both men and women in the overall study, but only interviewed women who had not completed their programme. Two studies targeted older adults: community dwelling (Johnson et al. 2001), and in residential care (O'Dell et al. 2008). Three studies were specific to women with stress urinary incontinence (Hay-Smith et al. 2007; MacInnes, 2008; Sarma et al. 2009); the remaining studies included people with mixed types of urinary incontinence. One study did not exclude participants 
who were continent at the time of interview (9/38 participants reported no or rare wetness), but who had experience of self-care strategies (Milne \& Moore, 2006).

Two studies were not specific to a particular type of behavioural intervention, but included material relevant to uptake of or adherence to behavioural self-care strategies (Milne \& Moore, 2006; O'Dell et al. 2008). One study elicited preferences for treatment, including behavioural options (Johnson et al. 2001). Three studies concerned client experiences with pelvic floor muscle training (PFMT) (HaySmith et al. 2007; Maclnnes, 2008; Sarma et al. 2009); and one study concerned client experience of a combined intervention using both PFMT and bladder training (Kincade et al. 1999).

One study explored the treatment preferences of frail older nursing home residents (Johnson et al. 2001); and two studies explored reasons for drop-out/withdrawal from treatment ((Kincade et al. 1999; Maclnnes, 2008). The remaining four (Milne \& Moore, 2006; Hay-Smith et al. 2007; O'Dell et al. 2008; Sarma et al. 2009) studies were more wide ranging, covering factors influencing uptake and/or adherence.

<Insert Table 1 here $>$

Quality and generalisability of included studies: Two studies met most of the appraisal criteria, where any weaknesses were unlikely to impact on the credibility of findings (Milne \& Moore 2006, Hay-Smith et al. 2007). Two studies had weaknesses mainly in the description of analysis such that weaknesses had the potential to impact on the credibility of the findings (Kincade et al. 1999, O'Dell et al. 2008). The qualitative methods in three studies were poorly described (Johnson et al. 2001, Maclnnes 2008, Sarma et al. 2009).

The included studies are mostly generalisable only to women. All of the studies required participants to be cognitively able to participate. In the main, sampling was purposive or a self-selected volunteer sample. Two studies drew samples from US residential care (Johnson et al. 2001, O'Dell et al. 2008), so findings may not be generalisable to other care systems. Two studies focus on relatively younger women with stress urinary incontinence (Hay-Smith et al. 2007, MacInnes 2008); one study (Sarma et al. 2009) also includes women with stress urinary incontinence but the age range is not reported. Two studies focus on older women (Kincade et al. 1999, Milne \& Moore 2006) with mixed types of incontinence. The study by O'Dell et al. (2008) included residents with pelvic floor dysfunction where 23 people out of 25 had urinary incontinence, but 13 out of 25 also had other problems. However, findings are defined by the different conditions and in the main it is clear when findings are referring to urinary incontinence. Johnson et al. (2001) included proxy respondents without urinary incontinence. 


\section{Findings related to the choice/uptake of behavioural treatments}

Table 2 details the results of the three studies considering factors impacting on choice or uptake of behavioural treatments for UI (Johnson et al. 2001, O’Dell et al. 2008, Sarma et al. 2009). Two studies considered the treatment preferences of older adults in long term care facilities in the USA (Johnson et al. 2001, O'Dell et al. 2008), while Sarma et al. (2009) interviewed women with stress urinary incontinence attending a tertiary urogynaecology unit in Australia about perseverance with pelvic floor muscle exercises. Results suggest that clients may have a higher tolerance for symptoms and a lower tolerance for disturbance, with a preference for interventions promoting independence and comfort, and resistance to any invasive intervention. Behavioural interventions such as prompted voiding can be viewed as embarrassing and resulting in dependence on others, with residents in care facilities disliking the subsequent reliance on nursing staff.

$<$ Insert Table 2 here $>$

\section{Participation/adherence}

Table 3 details the results of three studies considering factors impacting on participation in and adherence to behavioural interventions. Two studies (Hay-Smith et al. Sarma et al. 2009) were specific to PFMT, while Milne \& Moore (2006) referred to client factors impacting on adherence to both BT and PFMT.

\section{$<$ Insert Table 3 here>}

For BT, a barrier to adherence was increased fear of accidents, while for both BT and PFMT, respondents identified difficulty with developing a routine and fitting the intervention into daily life, but a feeling of mastery and control if successful. Enablers included realistic goals, and adaptation of daily routines.

There were negative perceptions of PFMT, including the difficulty of learning the exercises and knowing whether they were done correctly. Respondents valued feedback and follow up. Contextual features that impacted on adherence included the requirement for privacy. All three studies were conducted with women; two were specific to women with stress UI (Hay-Smith et al. 2007, Sarma et al. 2009).

\section{Withdrawal/drop-out}


Two studies considered women's reasons for withdrawal from behavioural UI programmes where PFMT was a major component. The findings are detailed in Table 4.

\section{<Insert Table 4 here>}

Women cited other health problems, competing pressures, the inconvenience of attending clinics, and negative perceptions of PFMT as barriers. Because of the difficulty of knowing whether practice was successful, feedback was viewed as helpful by some respondents in both studies. Both of these studies were completed on non-attenders of established continence clinics, so the results may not be generalisable beyond these specific examples.

\section{Summary: client experiences}

Client factors: Uptake and maintenance of behavioural therapies could be affected by clients' values and lifestyle preferences, prior experiences with behavioural therapies, and their perceptions of the potential consequences - both positive and negative. Adherence was helped by having realistic goals and expectations, and experiencing the positive consequences of success.

Intervention factors: The difficulty of knowing whether PFMT exercises are done correctly, and of fitting interventions into daily life were barriers. Professional follow up and feedback helped adherence, as did tailoring interventions to the individual's needs and routines.

Contextual factors: The convenience or cost of treatment options could affect adherence, as could the availability of a suitable environment for practice. People in residential care valued independence and preferred to avoid increased reliance on nursing staff. They could therefore show a preference for containment strategies for urinary incontinence, rather than behavioural therapies.

\section{Description of studies of staff experience}

Six studies elicited the opinions of staff about aspects of delivering behavioural interventions for $\mathrm{UI}$, and are summarised in Table 5.

\section{<Insert Table 5 here}

Five studies were completed in long term care facilities in the USA, and one in acute care in the UK. One study mainly referred to factors influencing choice/uptake of UI treatments for older people in residential care (Johnson et al. 2001). Three studies detailed the factors influencing the provision of continence care: one in acute care settings (Dingwall \& McLafferty, 2006) and two in long term care settings (Mather \& Bakas, 2002; Resnick et al. 2006). Two studies focused on staff perceptions of 
delivering a prompted voiding intervention in long term care settings (Lekan-Rutledge et al. 1998; Remsburg et al. 1999).

Two studies used questionnaires to collect data (Lekan-Rutledge et al. 1998, Remsburg et al. 1999); four studies used group interviews or focus groups, with two of these studies also using a small number of individual interviews (Johnson et al. 2001, Dingwall \& McLafferty 2006). All of the studies collected data from nurses, four studies collected data from mixed grades of nursing staff, with two studies specific to nursing assistants (Lekan-Rutledge et al. 1998, Mather \& Bakas 2002). Two studies (Lekan-Rutledge et al. 1998, Remsburg et al. 1999) were undertaken to elicit the views of staff about a prompted voiding intervention they had participated in; the remaining four studies were about views on aspects of general continence care that could include behavioural intervention.

Quality and generalisability: The quality of the studies related to staff views was poor overall, with only one study of good quality (Resnick et al. 2006), and two studies of moderate quality (Mather \& Bakas 2002, Dingwall \& McLafferty 2006). In the main, findings are most relevant to nursing staff working in long term care settings in the USA. There is only one study relevant to acute care in the UK. However, most studies report barriers to the provision of adequate continence care (including forms of behavioural intervention) to older people. The generalisability of most of the findings related to barriers are confirmed in both acute and long term care settings, in the USA and the UK. However, the generalisability of findings related to enablers is mostly confined to nursing assistants working in long term care settings in the USA.

$<$ Insert Table 6 here>

\section{Summary: staff perceptions}

Factors which could act as a barrier to continence promotion by staff included views on UI in older people; different views on aims of UI therapy than clients or family; referral and admission routes; nursing assessment procedures; staff motivation and education; lack of staff and conflicting work priorities; the requirements of manual handling; perceptions of treatment effectiveness; and scheduling conflicts.

Factors that could act as enablers of continence promotion included education; teamwork; adequate staffing; methods of work allocation; sufficient and appropriate equipment and supplies; and experience of success. 
The two studies specific to the nursing assistant role in the promotion of continence or the implementation of prompted voiding (Lekan-Rutledge et al. 1998, Mather \& Bakas 2002) also identified methods to improve management of the nursing assistant contribution to care. These included regular assignments; inclusion in the plan of care; increased accountability for adhering to a toileting plan; more autonomy and freedom to prioritise; recognition and reward of contribution to continence promotion and management; and identification of role models.

\section{DISCUSSION}

Seven studies involving 200 participants identified clients' views of factors that could act as a barrier to continence promotion. Findings identified from at least one study of moderate quality included increased fear of accidents; attitude to exercises and fitting them into daily life; competing interests; convenience and cost of treatment; and views about the suitability of the intervention. For older people in residential care influencing factors included a tolerance for UI symptoms and a preference for interventions that facilitated independence from staff. Factors that could enable participation from the clients' perspective included having realistic goals and expectations; gaining a sense of mastery and control; help with adapting daily routines; feedback on performance and professional follow up; and the availability of suitable facilities in residential care.

Six studies involving 427 participants (mainly nurses in residential or acute care) identified staff views of factors that could act as a barrier to continence promotion. Findings identified from at least one study of moderate quality included views of staff about the aims of treatment; routes of admission and referral; lack of suitable assessments and involvement of the wider care team; staff motivation and education; conflicting work priorities, requirements of manual handling and lack of staff; and perceptions of treatment effectiveness. Factors that could enable the promotion of continence included staff education; teamwork, adequate staffing and appropriate methods of work allocation; sufficient and appropriate equipment and supplies; and experience of success.

The quality of studies was mixed, with the potential for bias originating in the main from poor description of methods of data analysis, or methods of testing the robustness of the findings. However, most of the qualitative studies were descriptive rather than in-depth studies, so the identification and listing of potential barriers and facilitators to the delivery or uptake of behavioural interventions is unlikely to be problematic, in terms of interpretation or synthesis. Only a small amount of data was extracted from the descriptive component of the two surveys (Remsburg et al. 1999, Johnson et al. 2001), such as frequency of agreement with barriers to the use of behavioural 
methods for continence promotion, or additional barriers identified in free text responses. However, most of the findings were supported by at least one study of moderate quality.

While there were 13 studies included in the narrative analysis focusing on broadly the same topic, there was relatively little overlap between their specific focus, with three studies of treatment choice; three of treatment adherence; two of treatment withdrawal; two of PV implementation; two of continence promotion in long term care, and one in acute care. Only one study (Hay-Smith et al. 2007) collected detailed information about clients' experiences of a particular behavioural therapy i.e. PFMT, so there is in fact very little in-depth exploration of client responses to behavioural therapies.

The available evidence for clients relates to cognitively able women in the main, but apart from that similarity, the samples differed. Three studies were restricted to women with stress UI, and the samples in two of these studies were younger. Three of the studies related to older women in residential care, and one study was a community sample. The mix of samples and the different focus of the studies means that the barriers and enablers identified should be viewed as context specific, rather than generalisable to any client group or setting.

There is very little information relating to client experiences of behavioural therapies other than PFMT, and none of the studies were longitudinal, so not much is known about how views might change and develop over time. There is very little information about particular sub-groups, e.g. those with severe or mild incontinence, or about men's experience of behavioural therapies.

The available evidence for staff all relates to nursing staff, predominantly those working in long term residential care, although one study was undertaken in acute care. The samples of four of the studies included a mix of grades from nursing assistant through to charge nurse and Director of Nursing. The identified barriers and enablers related in the main to the direct delivery of care and although two studies did take a rather wider view that included some system features, there is not a strong whole systems approach overall. The focus on behavioural therapies in the general studies of continence care was rather small, with the impression being that nurses did not know much about them. There were no studies in a community setting, and none relevant to the delivery of a specific behavioural therapy other than prompted voiding.

The literature suggests that careful attention needs to be paid to the specific barriers to change in any given setting, identified through 'diagnostic analysis' at levels that may include the individual, groups or teams, organisations and the wider health-care system (Ferlie \& Shortell 2001). Further research on barriers and facilitators to implementing behavioural interventions from the perspective of clients and staff is required in order to enable tailoring of implementation strategies in terms of 
both the adaptation of evidence to local clinical settings (Graham et al. 2006), and the selection of strategies to change professional practice that take account of recognised obstacles to, or enablers of, implementation (Baker et al. 2010).

These gaps were addressed within the Identifying Continence OptioNs after Stroke (ICONS) feasibility trial. This was done by exploring questions with patients related to subjective experiences of continence care (e.g. attitudes to behavioural interventions, expectations, how correct performance was assessed etc.) and included an in depth exploration of barriers to and enablers of introducing BT and PV with nursing and other clinical staff involved in continence care (Thomas et al. 2014; 2015).

The ICONS intervention was informed by the findings of the evidence synthesis on the barriers and enablers to successful implementation of behavioural interventions for $\mathrm{UI}$ in line with the MRC framework for developing and evaluating complex interventions (Medical Research Council 2008). For example, we added a section to the patient education booklet entitled 'what other people have said": this included motivational quotations from clients in the review (e.g. "Set yourself small goals for improvement", "Do not give up" and "Do not be embarrassed - this is a common condition") (Thomas et al. 2015).

\section{Limitations of the review process}

The synthesis of qualitative data is not a straightforward mechanical process, and some issues were encountered that need to be taken into consideration when reading the review findings. In the main, we identified the study authors' themes, categories and codes as findings, i.e. secondary data. Identified factors could therefore be based on one or many respondents' views, and we have not differentiated or made any interpretation of relative importance or size of impact. We have only grouped similar or related factors and identified where multiple studies have described the same factor. Factors were classified as barriers and enablers but many more barriers were identified than enablers, and sometimes factors could be interpreted as either. Factors were also classified as relating to different stages in the process of treatment: uptake, participation, and withdrawal. We used our judgement to assign factors to the most appropriate stage or direction of effect. Where it was possible to infer from the original, factors are reported as related to a specific therapy such as prompted voiding, but some studies were more related to generic management of incontinence with behavioural therapy. 


\section{CONCLUSION}

There is very little detailed exploration of clients' experiences of, and responses to, behavioural interventions, with the exception of one in-depth study focussing on PFMT. Similar in-depth research on clients' experiences of other types of behavioural interventions are warranted in order to understand why people do or do not adhere to these therapies. Evidence of staff experiences is limited to nursing staff and relates predominantly to prompted voiding in long-term residential care; there are no studies evaluating the delivery of behavioural interventions in rehabilitation settings. Studies of the uptake and delivery of other behavioural interventions in other settings are warranted. 
Reference List

Abraham C. and Michie S. (2008) A taxonomy of behavior change techniques used in interventions. Health Psychology 27(3), 379-387.

Abrams P., Cardozo L., Fall M., Griffiths D., Rosier P., Ulmsten U. et al. (2002) The standardisation of terminology of lower urinary tract function: report from the Standardisation Sub-committee of the International Continence Society. American Journal of Obstetrics and Gynecology 2002, 187: 116126.

Arunabh M.B., Badlani G. (1993) Urologic problems in cerebrovascular accidents. Problems in Urology, 7: 41-53.

Baker R., Camosso-Stefinovic J., Gillies C., Shaw E.J., Cheater F., Flottorp S., et al. (2010) Tailored interventions to overcome identified barriers to change: effects on professional practice and health care outcomes. Cochrane Database of Systematic Reviews 3, CD005470.

Barer D.H. (1989) Continence after stroke: useful predictor or goal of therapy? Age and Ageing 18(3), 183-191.

Basu M., Wise B., \& Duckett J. (2010) A quantitative and qualitative study of women's preferences for treatments of pelvic floor disorders. Neurourology and Urodynamics.Conference: Joint Annual Meeting of the International Continence Society, ICS and International Urogynecological Association, IUGA Toronto, Canada.Conference.

Booth J., Kumlien S., Zang Y., Gustafsson B., Tolson D. (2009) Rehabilitation nurses practices in relation to urinary incontinence following stroke: a cross-cultural comparison. Journal of Clinical Nursing 18(7),1049-1058.

Brittain K.R., Peet S.M., Potter J.F., Castleden C.M. (1999) Prevalence and management of urinary incontinence in stroke survivors. Age and Ageing, 28: 509-511.

Cowey E., Smith L.N., Booth J., Weir C.J. (2012) Urinary catheterization in acute stroke: clinical realities. A mixed methods study. Clinical Rehabilitation 26(5), 470.

Critical Appraisal Skills Programme, 2013. http://www.casp-uk.net/ (accessed 15 th July 2013)

Davidson K.W., Goldstein M., Kaplan R.M., Kaufmann P.G., Knatterud G.L., Orleans C.T., Spring B., Trudeau K.J., Whitlock E.P. (2003) Evidence-based behavioral medicine: what is it and how do we achieve it? Annals of Behavioral Medicine 26 (3), 161-171.

Dingwall L., McLafferty E. (2006) Do nurses promote urinary continence in hospitalized older people?: An exploratory study. Journal of Clinical Nursing 15 (10), 1276-1286.

Diokno A., Yuhico M. Jr. (1995) Preference, compliance and initial outcome of therapeutic options chosen by female patients with urinary incontinence. Journal of Urology 154 (5), 1727-1730.

Dumoulin C., Hay-Smith E.J., Mac Habee-Seguin G. (2014) Pelvic floor muscle training versus no treatment, or inactive control treatments, for urinary incontinence in women. Cochrane Database of Systematic Reviews 5, CD005654.

Eustice S., Roe B., Paterson J. (2000) Prompted voiding for the management of urinary incontinence in adults. Cochrane Database of Systematic Reviews (2), CD002113.

Ferlie E.B., Shortell S.M. (2001) Improving the quality of health care in the United Kingdom and the United States: a framework for change. Milbank Quarterly 79, 281-315. 
Graham I.D., Logan J., Harrison M.B., Straus S.E., Tetroe J., Caswell W. et al. (2006) Lost in knowledge translation: time for a map? Journal of Continuing Education in the Health Professions 26, 13-24.

Hay-Smith E.J.C., Ryan K., Dean S. (2007) The silent, private exercise: experiences of pelvic floor muscle training in a sample of women with stress urinary incontinence. Physiotherapy 93(1), 53-61.

Hsieh H. F. \& Shannon S. E. (2005) Three approaches to qualitative content analysis. Qualitative Health Research 15(9), 1277-1288.

Intercollegiate Stroke Working Party. (2012) National clinical guideline for stroke (4 ${ }^{\text {th }}$ edition). Royal College of Physicians, London.

Johnson T.M., Ouslander J.G., Uman G.C., Schnelle J.F. (2001) Urinary incontinence treatment preferences in Long-Term Care. Journal of the American Geriatrics Society 49(6), 710-718.

Jorgensen L., Engstad T., Jacobsen B.K. (2005) Self-reported urinary incontinence in noninstitutionalized long-term stroke survivors: A population-based study. Archives of Physical Medicine and Rehabilitation 86(3), 416-420.

Kincade J.E., Johnson T.M., Ashford-Works C., Clarke M.K., Busby-Whitehead J. (1999) A pilot study to determine reasons for patient withdrawal from a pelvic muscle rehabilitation program for urinary incontinence. The Journal of Applied Gerontology 18, 379-396.

Kolominsky-Rabas P.L., Hilz M.J., Neundoerfer B., Heuschmann P.U. (2003) Impact of urinary incontinence after stroke: results from a prospective population-based stroke register. Neurourology and Urodynamics 22(4), 322-327.

Lawrence E.S., Coshall C., Dundas R., Stewart J., Rudd A.G., Howard R., Wolfe C.D.A. (2001) Estimates of the prevalence of acute stroke impairments and disability in a multiethnic population. Stroke 32(6), 1279-1284.

Lekan-Rutledge D., Palmer M.H., Belyea M. (1998) In their own words: nursing assistants' perceptions of barriers to implementation of prompted voiding in long-term care. Gerontologist 38 (3), 370-378.

Lennard F. J. (2009) Reasons why patients referred to physiotherapy with continence or pelvic floor dysfunction fail to complete treatment. Journal of the Association of Chartered Physiotherapists in Women's Health (105), 56-63.

Levy-Storms L., Schnelle J.F., Simmons S.F. (2007) What do family members notice following an intervention to improve mobility and incontinence care for nursing home residents? An analysis of open-ended comments. Gerontologist 47 (1), 14-20.

Maclnnes C.L. (2008) Why women leave therapy for stress incontinence. Nursing Times 104 (41), 5053.

Marinkovic S.P., Badlani G. (2001) Voiding and sexual dysfunction after cerebrovascular accidents. Journal of Urology 165(2), 359-370.

Mather K.F., Bakas T. (2002) Nursing assistants' perceptions of their ability to provide continence care. Geriatric Nursing 23 (2), 76-81.

McVean R. J., Orr A., Webb A. K., Bradbury A., Kay L., Philips E., and Dodd M. E. (2003) Treatment of urinary incontinence in cystic fibrosis. Journal of Cystic Fibrosis 2(4), 171-176.

Medical Research Council. (2000) A framework for the development and evaluation of RCTs for complex interventions to improve health. Medical Research Council, London. 
Medical Research Council. (2008) Developing and evaluating complex interventions: new guidance. Medical Research Council, London.

Milne J.L., Moore K.N. (2006) Factors impacting self-care for urinary incontinence. Urologic Nursing 26 (1), 41-51.

Nakayama H., Jorgensen H.S., Pedersen P.M., Raaschou H.O., Olsen T.S. (1997) Prevalence and risk factors of incontinence after stroke. The Copenhagen Stroke Study. Stroke 28(1), 58-62.

National Collaborating Centre for Women's and Children's Health. (2013) Urinary incontinence in women: the management of urinary incontinence in women. NICE Clinical Guideline CG171. London, National Institute for Health and Care Excellence.

National Institute for Health and Care Excellence. (2012) Urinary incontinence in neurological disease: management of lower urinary tract dysfunction in neurological disease. Clinical Guideline 148: Methods, evidence and recommendations. National Clinical Guideline Centre, London.

National Institute for Health and Care Excellence. (2007) Behaviour Change. NICE Public Health Guidance 6. National Institute for Health and Care Excellence, London.

O'Dell K.K., Jacelon C., Morse A.N. (2008) 'I'd rather just go on as I am' -- pelvic floor care preferences of frail, elderly women in residential care. Urologic Nursing 28 (1), 36-47.

Ostaszkiewicz J., Johnston L., Roe B. (2004a) Habit retraining for the management of urinary incontinence in adults. Cochrane Database of Systematic Reviews (2), CD002801.

Ostaszkiewicz J., Johnston L., Roe B. (2004b) Timed voiding for the management of urinary incontinence in adults. Cochrane Database of Systematic Reviews (1), CD002802.

Panicker J.N., de Sēze M., Fowler C.J. (2010) Neurogenic lower urinary tract dysfunction and its management. Clinical Rehabilitation 24: 579-589.

Patel M., Coshall C., Lawrence E., Rudd A.G., Wolfe C.D. (2001) Recovery from poststroke urinary incontinence: associated factors and impact on outcome. Journal of the American Geriatrics Society 49(9), 1229-1233.

Perry, S., Shaw, C., Assassa, P., Dallosso, H., Williams, K. et al. (2000) An epidemiological study to establish the prevalence of urinary symptoms and felt need in the community: the Leicestershire MRC Incontinence Study. Leicestershire MRC Incontinence Study Team. Journal of Public Health Medicine 22(3), 427-434.

Pettersen R., Stien R., Wyller T.B. (2007) Post-stroke urinary incontinence with impaired awareness of the need to void: clinical and urodynamic features. British Journal of Urology International, 99: 1073-1077.

Remsburg R.E., Palmer M.H., Langford A.M., Mendelson G.F. (1999) Staff compliance with and ratings of effectiveness of a prompted voiding program in a long-term care facility. Journal of Wound, Ostomy, \& Continence Nursing 26 (5), 261-269.

Resnick B., Keilman L.J., Calabrese B., Parmelee P., Lawhorne L., Pailet J., Ouslander J. (2006) Continence care. Nursing staff beliefs and expectations about continence care in nursing homes. Journal of Wound, Ostomy \& Continence Nursing 33 (6), 610-618.

Roe B., Milne J., Ostaszkiewicz J., Wallace S. (2007a) Systematic reviews of bladder training and voiding programmes in adults: a synopsis of findings on theory and methods using metastudy techniques. Journal of Advanced Nursing 57 (1), 3-14. 
Roe B., Ostaszkiewicz J., Milne J., Wallace S. (2007b) Systematic reviews of bladder training and voiding programmes in adults: a synopsis of findings from data analysis and outcomes using metastudy techniques. Journal of Advanced Nursing 57 (1), 15-31.

Rosqvist E., Aukee P., Kallinen M., \& Rantanen T. (2008) Feasibility and acceptability of the pelvic floor muscle and bladder training programme. International Journal of Urological Nursing, 2, (3) 113118.

Royal College of Physicians (2014) Sentinel Stroke National Audit Programme (SSNAP) Clinical audit April-June 2014 Public Report. London, Royal College of Physicians.

Sarma S., Hawthorne G., Thakkar K., Hayes W., Moore K.H. (2009) The development of an Incontinence Treatment Motivation Questionnaire for patients undergoing pelvic floor physiotherapy in the treatment of stress incontinence. International Urogynecology Journal Including Pelvic Floor Dysfunction 20 (9), 1085-1093.

Simmons S.F. and Ouslander J.G. (2005) Resident and family satisfaction with incontinence and mobility care: sensitivity to intervention effects? Gerontologist 45(3), 318-326.

St John W, Wallis M, Griffiths S, and McKenzie S. (2006) Daily-living self-management of persistent urinary incontinence: Comparisons between the self-management practices of people with $\mathrm{UI}$ and the recommendations of continence nurse specialists - (Abstract). International Continence Society Conference Papers Abstract 454.

Storey S., Aston M., Price S., Irving L., \& Hemmens E. (2009) Women's experiences with vaginal pessary use. Journal of Advanced Nursing, 65(11), 2350-2357.

Tannenbaum C., Drali R., Holroyd-Leduc J., \& Richard L. (2010) Lessons learned: Impact of a continence promotion activity for older community-dwelling women. Neurourology and Urodynamics 29 (4), 540-544.

Thomas J. \& Harden A. (2008) Methods for the thematic synthesis of qualitative research in systematic reviews. BMC Medical Research Methodology 8, 45.

Thomas L.H., Watkins C.L., French B., Sutton C.J., Forshaw D., Leathley M.J., Burton C.R., Cheater F., Roe B., Britt D., Booth J., McColl E., The ICONS Project Team and the ICONS Patient, Public and Carer Involvement Groups. (2014) ICONS: Identifying Continence OptioNs after Stroke: findings from a cluster randomised controlled feasibility trial. Trials 15: 509.

Thomas L.H., French B., Sutton C.J., Forshaw D., Leathley M.J., Burton C.R., Roe B., Cheater F.C., Booth J., McColl E., Carter B., Walker A., Brittain K., Whiteley G., Rodgers H., Barrett J. and Watkins C.L. on behalf of the ICONS: Identifying Continence OptioNs after Stroke project team and the ICONS Patient, Public and Carer Involvement Groups. (2015) ICONS: Identifying Continence OptioNs after Stroke: An evidence synthesis, case study and exploratory cluster randomised controlled trial of the introduction of a systematic voiding programme for patients with urinary incontinence after stroke in secondary care. Programme Grants for Applied Research 3(1).

Tong A., Flemming K., Mclnnes E., Oliver S., Craig J. (2012) Enhancing transparency in reporting the synthesis of qualitative research: ENTREQ. BMC Medical Research Methodology 12(1):181.

Wallace S.A., Roe B., Williams K., Palmer M. (2004) Bladder training for urinary incontinence in adults. 2000. Cochrane Database of Systematic Reviews (1), CD001308.

Williams K.S., Assassa R.P., Cooper N.J., Turner D.A., Shaw C., Abrams K.R., Mayne C., Jagger C., Matthews R., Clarke M., McGrother C.W., The Leicestershire MRC Incontinence Study Team. (2005) 
Clinical and cost-effectiveness of a new nurse-led continence service: a randomised controlled trial. British Journal of General Practice 55 (518), 696-703.

Williams M.P., Srikanth V., Bird M., Thrift A.G. (2012) Urinary symptoms and natural history of urinary continence after first-ever stroke--a longitudinal population-based study. Age and Ageing 41(3), 371-376.

Wyman J.F., Fantl J.A., McClish D.K., Bump R.C. (1998) Comparative efficacy of behavioral interventions in the management of female urinary incontinence. Continence Program for Women Research Group. American Journal of Obstetrics \& Gynecology 179 (4), 999-1007. 


\section{Appendix 1: MEDLINE search strategy}

1. exp urinary incontinence/

2. Urination/ or urodynamics/

3. Urinary catheterization/

4. Urinary bladder, neurogenic/

5. Urinary bladder, overactive/

6. Urination disorders/

7. Toilet training/

8. Incontinence pads/

9. Dysuria/ or nocturia/

10. Toilet training/

11. Incontinence pads/

12. Pelvic floor/

13. toilet\$.tw.

14. (incontinen\$ or continen\$).tw.

15. urodynamic\$.tw.

16. ((bladder or detrusor or vesic\$) adj5 (instability or stab\$ or unstable or irritab\$ or hyperreflexia or dys?ynerg\$ or dyskinesia or overactive\$)).tw.

17. (void\$ adj5 (prompt\$ or diar\$)).tw.

18. (urin\$ adj2 leak\$).tw.

19. dribbl\$.tw.

20. diaper\$.tw.

21. (bladder\$ adj2 (neuropath\$ or neurogen\$ or neurolog\$)).tw.

22. bodyworn\$.tw.

23. underpad\$.tw.

24. 1 or 2 or 3 or 4 or 5 or 6 or 7 or 8 or 9 or 10 or 11 or 12 or 13 or 14 or 15 or 16 or 17 or 18 or 19 or 20 or 21 or 22 or 23

25. ((pelvic or habit or bladder or toilet or sensory) adj5 (train\$ or re?train\$ or re?educat $\$$ or drill)).tw.

26. (timed void\$ or prompted void\$).tw.

27. 25 or 26

28. exp behavior therapy/

29. (behav\$ adj25 (therap\$ or intervention\$ or train\$ or re?train\$ or modif\$)).tw.

30. exp cognitive therapy/

31. (cognit\$ adj25 (therap\$ or intervention\$ or train\$ or re?train\$)).tw.

32. Combined Modality Therapy/

33. (skill\$ adj5 (train\$ or re?train\$)).tw.

34. *Health promotion/

35. Health Education/ or Patient Education as Topic/ 
36. exp *Exercise/

37. Motor skills/

38. Group processes/

39. Psychotherapy, group/

40. Social support/

41. ((group or social) adj5 support).tw.

42. Self care/

43. Cues/

44. Reminder Systems/

45. Tape recording/

46. exp motivation/

47. Feedback/

48. (monitor\$ or feedback or goal\$).tw.

49.28 or 29 or 30 or 31 or 32 or 33 or 34 or 35 or 36 or 37 or 38 or 39 or 40 or 41 or 42 or 43 or 44 or 45 or 46 or 47 or 48

50. 27 and 24

51.49 and 24

52. 27 and 49

53.52 or 50 or 51

54. Randomized Controlled Trials/

55. random allocation/

56. Controlled Clinical Trials/

57. control groups/

58. clinical trials/ or clinical trials, phase i/ or clinical trials, phase ii/ or clinical trials, phase iii/ or clinical trials, phase iv/

59. Clinical Trials Data Monitoring Committees/

60. double-blind method/

61. single-blind method/

62. Placebos/

63. placebo effect/

64. cross-over studies/

65. Multicenter Studies/

66. Therapies, Investigational/

67. Drug Evaluation/

68. Research Design/

69. Program Evaluation/

70. evaluation studies/

71. randomized controlled trial.pt. 
72. controlled clinical trial.pt.

73. clinical trial.pt.

74. multicenter study.pt.

75. evaluation studies.pt.

76. meta analysis.pt.

77. meta-analysis/

78. random\$.tw.

79. (controlled adj5 (trial\$ or stud\$)).tw.

80. (clinical\$ adj5 trial\$).tw.

81. ((control or treatment or experiment\$ or intervention) adj5 (group\$ or subject\$ or patient\$)).tw.

82. (surgical adj5 group\$).tw.

83. (quasi-random\$ or quasi random\$ or pseudo-random\$ or pseudo random\$).tw.

84. ((multicenter of multicentre or therapeutic) adj5 (trial\$ or stud\$)).tw.

85. ((control or experiment\$ or conservative) adj5 (treatment or therapy or procedure or manage\$)).tw.

86. ((singl\$ or doubl\$ or tripl\$ or trebl\$) adj5 (blind\$ or mask\$)).tw.

87. (coin adj5 (flip or flipped or toss\$)).tw.

88. latin square.tw.

89. versus.tw.

90. (cross-over or cross over or crossover).tw.

91. placebo\$.tw.

92. sham.tw.

93. (assign\$ or alternate or allocat\$ or counterbalance\$ or multiple baseline).tw.

94. controls.tw.

95. (treatment\$ adj6 order).tw.

96. (meta-analy\$ or metaanaly\$ or meta analy\$ or systematic review or systematic overview).tw.

97. or/54-96

98. 53 and 97

99. exp epidemiologic studies/

100. Intervention studies/ or Feasibility studies/ or Pilot projects/

101. exp Controlled Clinical Trial/

102. Nursing evaluation research/

103. Evaluation studies/ or multicenter study/

104. Program development/

105. behavioral research/ or empirical research/

106. (determinant\$ or factor\$ or barrier\$ or enabler\$ or facilitator\$ or predictor\$ or characteristic\$).tw. 
107. Guideline adherence/ or exp "outcome and process assessment (health care"/ or exp program evaluation/ or Guidelines as topic/ or Clinical Protocols/

108. Health plan implementation/

109. Organizational innovation/

110. Diffusion of innovation/

111. Patient compliance/

112. Patient satisfaction/

113. exp health behavior/

114. exp consumer satisfaction/

115. exp patient acceptance of health care/

116. Information dissemination/

117.99 or 100 or 101 or 102 or 103 or 104 or 105 or 106 or 107 or 108 or 109 or 110 or 111 or 112 or 113 or 114 or 115 or 116

118. 53 and 117

119. exp Pregnancy/

120. 98 or 118

121. 120 not 119

122. Child/ or Adolescent/

123. Adult/

124. 122 not 123

125. 121 not 124

126. limit 125 to english language

127. exp *Prostatectomy/

128. 126 not 127 


\section{Appendix 2: Studies excluded from the review}

\begin{tabular}{ll}
\hline Study & Reason for exclusion \\
\hline Basu 2010 & Includes treatment of prolapse as well as stress urinary incontinence \\
\hline $\begin{array}{l}\text { Diokno and } \\
1995\end{array}$ & $\begin{array}{l}\text { Yuhico } \\
\text { Only provides data relating to frequencies of choice, no data relating to } \\
\text { barriers and enablers of choice. }\end{array}$ \\
\hline Leonard 2009 & $\begin{array}{l}\text { Not possible to separate patients with urinary incontinence from those } \\
\text { with pelvic floor dysfunction }\end{array}$ \\
\hline Rosqvist 2008 & No data provided on barriers and enablers \\
\hline St John 2006 & $\begin{array}{l}\text { Not related to behavioural treatment. } \\
\text { relating to barriers and enablers of choice. }\end{array}$ \\
\hline Simons 2005 & $\begin{array}{l}\text { Not possible to separate patients with urinary incontinence from those } \\
\text { with pelvic organ prolapse }\end{array}$ \\
\hline Storey 2009 & $\begin{array}{l}\text { Collects data to test reliability of different response formats, no data } \\
\text { relating to barriers and enablers of choice. }\end{array}$ \\
\hline Levy-Storms 2007 & Confounded by medical condition, therefore cannot attribute data to Ul. \\
\hline McVean 2003 & $\begin{array}{l}\text { Collects data to compare client and professional ratings, no data relating } \\
\text { to barriers and enablers of choice. }\end{array}$ \\
\hline Tannenbaum 2008 & \\
\hline
\end{tabular}


Table 1: Description of studies of client experience

\begin{tabular}{|c|c|c|c|}
\hline Study & Client & Method & Focus \\
\hline $\begin{array}{l}\text { Kincade et al. } 1999 \\
\text { USA }\end{array}$ & Women, UI $(n=10)$ & Interviews & $\begin{array}{l}\text { Combined } \\
\text { intervention }\end{array}$ \\
\hline $\begin{array}{l}\text { Johnson et al. } 2001 \\
\text { USA }\end{array}$ & Frail older adults, UI (n=79) & Postal survey & Ul treatment \\
\hline $\begin{array}{l}\text { Milne \& Moore } 2006 \\
\text { Canada }\end{array}$ & Individuals, UI (n=38) & $\begin{array}{l}\text { Interviews + focus } \\
\text { groups }\end{array}$ & Self-care strategies \\
\hline $\begin{array}{l}\text { Hay-Smith et al. } 2007 \\
\text { New Zealand }\end{array}$ & Women, SUI $(n=20)$ & Interviews & PFMT \\
\hline $\begin{array}{l}\text { O'Dell et al. } 2008 \\
\text { USA }\end{array}$ & Older women, UI $(n=25)$ & Interviews & Pelvic floor care \\
\hline $\begin{array}{l}\text { Maclnnes } 2008 \\
\text { UK }\end{array}$ & Women, SUI $(n=12)$ & $\begin{array}{l}\text { Telephone } \\
\text { interviews }\end{array}$ & PFMT \\
\hline Sarma 2009 & Women, SUI $(n=16)$ & Interviews & PFMT \\
\hline
\end{tabular}

$\mathrm{UI}=$ urinary incontinence, $\mathrm{SUI}=$ stress urinary incontinence, $\mathrm{PFMT}=$ pelvic floor muscle training 
Table 2: Findings of client views studies: factors impacting on choice/uptake

\begin{tabular}{ll}
\hline BARRIERS & ENABLERS
\end{tabular}

\section{CLIENT FACTORS}

High tolerance for pelvic floor dysfunction (PFD) Interventions need to be suitable for the symptoms (O'Dell et al. 2008)

individual's needs (Johnson et al. 2001)

Dislike of embarrassment, public, personal, smell (Sarma et al. 2009)

Dislike of inconvenience in everyday activities (Sarma et al. 2009)

Increase in severity (Sarma et al. 2009)

Hope (Sarma et al. 2009)

Doing something for yourself/acknowledging the problem (Sarma et al. 2009)

UI management could disturb sleep ( $O^{\prime}$ Dell et al. 2008)

INTERVENTION FACTORS

$P V$ is viewed as difficult, results in dependence, and embarrassing (Johnson et al. 2001)

Resistance to the idea of a pelvic examination (O'Dell et al. 2008, Johnson et al. 2001)

Older adults aim was for containment of incontinence, with preference for independence, and no further testing or intervention (O'Dell et al. 2008)

Older adults' main criteria were that the intervention should be easy and not foster dependence, and be natural, comfortable and non-invasive; other criteria were that the intervention should not be embarrassing, and be dry, odour free, simple and not bulky (Johnson et al. 2001)

Anti-surgery sentiment (Sarma et al. 2009)

\section{CONTEXT FACTORS}

Respondents perceived staff to be unable or unwilling to implement UI interventions (Johnson et al. 2001)

Being unable to use bathroom because of safety restrictions (O'Dell et al. 2008)

Close proximity and availability of a clean bathroom (PV) (O'Dell et al. 2008)

Delays between asking for and receiving help (O'Dell et al. 2008) 
Fear of consequences (e.g. nursing

home)(Sarma et al. 2009)

Findings in italics are from studies where weaknesses in study design are likely to affect credibility. 
Table 3 Findings of client views studies: factors impacting on participation/adherence

\begin{tabular}{|c|c|c|}
\hline \multicolumn{2}{|c|}{ BARRIERS } & ENABLERS \\
\hline \multicolumn{3}{|c|}{ CLIENT FACTORS: } \\
\hline BT & $\begin{array}{l}\text { Increased fear of being wet, difficulty } \\
\text { of fitting into daily life (Milne and } \\
\text { Moore 2006) }\end{array}$ & $\begin{array}{l}\text { Sense of mastery for some if successful (Milne } \\
\text { and Moore 2006) }\end{array}$ \\
\hline \multirow[t]{4}{*}{ PFMT } & $\begin{array}{l}\text { Trying to develop routines, finding the } \\
\text { time and remembering to do exercises } \\
\text { (Hay-Smith et al. 2007) }\end{array}$ & $\begin{array}{l}\text { Maintaining an exercise routine, adapting a } \\
\text { number of daily routines and accommodating } \\
\text { treatment to own life (Milne and Moore 2006) }\end{array}$ \\
\hline & $\begin{array}{l}\text { Competing interests (UI could have } \\
\text { only minor psychosocial impact) (Milne } \\
\text { and Moore 2006) }\end{array}$ & $\begin{array}{l}\text { Mastery of exercises and regaining control } \\
\text { were valued (Hay-Smith et al. 2007) }\end{array}$ \\
\hline & $\begin{array}{l}\text { Co-morbidities (Sarma et al. 2009) } \\
\text { Confidence (Sarma et al. 2009) }\end{array}$ & $\begin{array}{l}\text { Having realistic goals and expectations (Milne } \\
\text { and Moore 2006) }\end{array}$ \\
\hline & & $\begin{array}{l}\text { Adapting a number of daily routines and } \\
\text { accommodating treatment to own life (Hay- } \\
\text { Smith et al. 2007) }\end{array}$ \\
\hline
\end{tabular}

INTERVENTION FACTORS

PMFT Hard to understand how to do the exercises (Hay-Smith et al. 2007, Sarma et al. 2009), exercises viewed as boring, a chore, tedious etc. (HaySmith et al. 2007)

Difficulty knowing whether exercises were done correctly (Milne and Moore 2006)

Difficult to continue without noticeable Regular follow up, professional involvement and feedback, awareness and affirmation of progress (Milne and Moore 2006)

Confirmation by palpation seen as helpful by at least one woman (Hay-Smith et al. 2007)

Preferences for exercise type (Hay-Smith et al. 2007)

Exercise support groups (Sarma et al. 2009) benefit (Hay-Smith et al. 2007)

Forgetting to do PFMT despite memory joggers (Sarma et al. 2009)

Lack of available time (Sarma et al. 2009)

\begin{tabular}{lll}
\hline CONTEXT FACTORS \\
\hline PFMT & $\begin{array}{l}\text { Some women felt they needed privacy } \\
\text { which limited the times/places they } \\
\text { could do exercises (Hay-Smith et al. }\end{array}$ & $\begin{array}{l}\text { Some women felt they could do exercises } \\
\text { anywhere (Hay-Smith et al. 2007) }\end{array}$ \\
$\begin{array}{l}\text { 2007) } \\
\text { Role of incontinence specialist (Sarma et al. } \\
\text { Cost of private physiotherapy (Milne }\end{array}$ & \\
and Moore 2006) &
\end{tabular}


Table 4 Findings of client views studies: factors impacting on withdrawal/drop-out

\begin{tabular}{ll}
\hline BARRIERS & ENABLERS
\end{tabular}

\section{CLIENT FACTORS}

Negative experiences, attitudes or feelings toward

PFMT (Kincade et al. 1999, Maclnnes 2008)

Other health problems (Kincade et al. 1999,

MacInnes 2008)

Forgotten appointments (Maclnnes 2008)

Unwilling to practice PFMT exercises: too many other demands, not enough energy (Kincade et al.

1999)

\section{INTERVENTION FACTORS}

Treatment not perceived to be appropriate or

effective for Ul status (Kincade et al. 1999)

PFMT exercises are boring (Kincade et al. 1999)

Unable to tell if effective without biofeedback (Kincade et al. 1999)

Preference for delivery mode e.g. group vs

Biofeedback for PMFT perceived to be helpful (Kincade et al. 1999)

individual (Kincade et al. 1999)

\section{CONTEXT FACTORS}

Other social demands e.g. caring role, housing issues (Maclnnes 2008)

Problems with billing (Kincade et al. 1999)

Problems with travel to the clinic for older people

(Kincade et al. 1999)

Treatment inconvenience: clinic conflicts with work demands for younger people (Kincade et al. 1999), no evening clinic (Maclnnes 2008)

Findings in italics are from studies where weaknesses in study design are likely to affect credibility. 
Table 5 Description of studies of staff experience

\begin{tabular}{llll}
\hline Study & Staff group & Data collection method & Focus \\
\hline Lekan-Rutledge et al. 1998 & $\begin{array}{l}\text { NA, LTC } \\
(n=141)\end{array}$ & Questionnaire & PV \\
\hline Remsburg et al. 1999 & $\begin{array}{l}\text { Nursing, LTC } \\
(n=88)\end{array}$ & Questionnaire & PV \\
\hline Johnson et al. 2001 & $\begin{array}{l}\text { Nursing, LTC } \\
(n=66)\end{array}$ & Group interviews & Continence care \\
\hline Mather \& Bakas 2002 & $\begin{array}{l}\text { NA, LTC } \\
(n=31)\end{array}$ & Focus groups & Continence care \\
\hline Dingwall \& McLafferty 2006 & $\begin{array}{l}\text { Nursing, } \\
\text { acute (n=63) }\end{array}$ & $\begin{array}{l}\text { Focus groups, } \\
\text { interviews }\end{array}$ & Continence care \\
\hline Resnick et al. 2006 & $\begin{array}{l}\text { Nursing, LTC } \\
(n=38)\end{array}$ & Focus groups & Continence care \\
\hline
\end{tabular}

$\mathrm{NA}=$ nursing assistant, $\mathrm{PV}=$ prompted voiding, $\mathrm{LTC}=$ long term care 
Table 6. Findings of staff views studies relating to client and intervention characteristics

\begin{tabular}{|c|c|}
\hline BARRIERS & ENABLERS \\
\hline \multicolumn{2}{|l|}{ CLIENT } \\
\hline \multicolumn{2}{|l|}{$\begin{array}{l}\text { Acute care nurses can view UI as a factor of old } \\
\text { age, with a focus on containment rather than } \\
\text { continence promotion (Resnick et al. 2006, } \\
\text { Dingwall and McLafferty 2006). Nurses think } \\
\text { clients may accept or hide UI (Dingwall and } \\
\text { McLafferty 2006) with treatment acceptance } \\
\text { dependent on duration of UI, and past coping } \\
\text { strategies (Dingwall and McLafferty 2006) }\end{array}$} \\
\hline \multicolumn{2}{|l|}{$\begin{array}{l}\text { Factors affecting whether continence promotion } \\
\text { strategies were used by nurses included: }\end{array}$} \\
\hline $\begin{array}{l}\text { Pain, functional ability (Resnick et al. 2006, } \\
\text { (Dingwall and McLafferty 2006) }\end{array}$ & $\begin{array}{l}\text { Focus on improving pain and function } \\
\text { (Resnick et al. 2002) }\end{array}$ \\
\hline $\begin{array}{l}\text { Cognitive ability, client ability to communicate and } \\
\text { retain information (Dingwall and McLafferty 2006) } \\
\text { cooperation and motivation (Mather and Bakas } \\
\text { 2002, Dingwall and McLafferty 2006) }\end{array}$ & $\begin{array}{l}\text { Nurses' assessment of incontinence status } \\
\text { and selection of appropriate residents for PV } \\
\text { (i.e. those who are "able and willing" (key } \\
\text { issue) (Lekan-Rutledge et al. 1998) }\end{array}$ \\
\hline Depression (Dingwall and McLafferty 2006) & \multirow{3}{*}{$\begin{array}{l}\text { Get to know residents' toileting schedule } \\
\text { (Resnick et al. 2006) }\end{array}$} \\
\hline $\begin{array}{l}\text { Psychosocial problems: laziness, denial of the } \\
\text { problem, not wanting to ask to urinate, fear of } \\
\text { falling, resident embarrassed to ask for help } \\
\text { (Resnick et al. 2006) }\end{array}$ & \\
\hline $\begin{array}{l}\text { For some residents the intervention (PV) does not } \\
\text { make a difference/no change in wetness noted } \\
\text { (Remsburg et al. 1999) }\end{array}$ & \\
\hline
\end{tabular}

Nurses used criteria related to avoidance of infection and increase in self-esteem more than clients or family; and used criteria relating to comfort, non-invasiveness and effectiveness less than residents or family (Johnson et al. 2001)

\section{INTERVENTION}

Improved efficiency of pads may be a reason for not promoting continence: staff view patients as comfortable, dry, $\mathrm{UI}$ is not visible, odour is reduced (Dingwall and McLafferty 2006)

Pads may be used alongside continence promotion, but that can make it harder to toilet (Dingwall and McLafferty 2006)
Get clothes that are easy to pull on/off (Resnick et al. 2002) 
Staff views on interventions e.g. PFMT not viewed as a nursing role (Dingwall and McLafferty 2006), $P V$ viewed as too time-consuming (Remsburg et al. 1999)

Procedures may not be followed appropriately (Remsburg et al. 1999, Dingwall and McLafferty 2006)

\section{CONTEXT}

Clients with UI on admission or those transferred from another area with UI are less likely to be assessed with a view to promotion of continence (Dingwall and McLafferty 2006)

Nurses' dissatisfaction with assessment procedures, particularly around tools used and with multidisciplinary involvement in assessment. Assessment viewed as nursing role rather than multidisciplinary, with lack of referral to specialists (Dingwall and McLafferty 2006)

Inconsistency of approach, variations in staff supportiveness for programmes, staff disinterest (Lekan-Rutledge et al. 1998, Resnick et al. 2006, Dingwall and McLafferty 2006)

Lack of staff education around: types of UI, approaches to continence promotion, and psychological and social impact of UI (Resnick et al. 2006, Dingwall and McLafferty 2006)

Lack of communication, cooperation, and teamwork (Mather and Bakas 2002, Resnick et al. 2006)

Lack of staff, low staffing levels, and lack of qualified staff for workloads (Lekan-Rutledge et al. 1998, Mather and Bakas 2002, Dingwall and McLafferty 2006)

Conflicting demands/priorities of staff (LekanRutledge et al. 1998, Resnick et al. 2006, Dingwall and McLafferty 2006)
Education about the importance and benefit of treatment (Lekan-Rutledge et al. 1998, Resnick et al. 2006, Mather and Bakas 2002) Improve teamwork (Mather and Bakas 2002), staff communication and support (including monitoring) for PV (Lekan-Rutledge et al. 1998)

Adequate staff to resident ratios (Mather and Bakas 2002, Resnick et al. 2006)

Consider alternative means of $P V$ implementation e.g. team, limit the number of residents on PV (Lekan-Rutledge et al. 1998) 
McLafferty 2006), staff can't transfer alone and can't get help in time (Resnick et al. 2006)
Transform the environment to facilitate function (Resnick et al. 2006)

Provide sufficient supplies e.g. commodes, appropriate toilets, toilet lifts, better toilets/commodes, better lifts to help transfers (Resnick et al. 2006)
Negative attitude about the effectiveness of treatments (Resnick et al. 2006)
Staff felt rewarded when approaches were successful (Dingwall and McLafferty 2006)

Scheduling conflict - patient at therapy or appointments (Resnick et al. 2006)

Findings in italics are from studies where weaknesses in study design are likely to affect credibility. 


\begin{tabular}{|c|c|c|c|c|c|c|c|c|}
\hline & $\begin{array}{l}\text { SUMMARY OF QUALITY - QUALITATI VE STUDI ES: } \\
\text { CLI ENT VIEWS }\end{array}$ & $\begin{array}{l}\text { Hay- } \\
\text { Smith }\end{array}$ & $\begin{array}{l}\text { Milne \& } \\
\text { Moore }\end{array}$ & Johnson & Mclnnes & Kincade & O’Dell & Sarma \\
\hline Appropriate research design & Justification for design/method discussed/appropriate & $\sqrt{ }$ & $\sqrt{ }$ & $\sqrt{ }$ & $\sqrt{ }$ & $\mathrm{x}$ & $\sqrt{ }$ & $\sqrt{ }$ \\
\hline \multirow{3}{*}{ Sampling } & Clear explanation of how participants were selected & $\sqrt{ }$ & $\sqrt{ }$ & $\sqrt{ }$ & $x$ & $\overline{\sqrt{ }}$ & $\sqrt{ }$ & $\sqrt{ }$ \\
\hline & $\begin{array}{l}\text { Appropriateness of sample to provide knowledge sought by } \\
\text { study }\end{array}$ & $\sqrt{ }$ & $\sqrt{ }$ & $\sqrt{ }$ & $\sqrt{ }$ & $\sqrt{ }$ & $\sqrt{ }$ & $\sqrt{ }$ \\
\hline & Explanation of final sample and reasons for non-response & $\sqrt{ }$ & $\sqrt{ }$ & $\mathrm{x}$ & $x$ & $x$ & $\sqrt{ }$ & $x$ \\
\hline \multirow[b]{3}{*}{ Data collection } & $\begin{array}{l}\text { Clear explanation of what data were collected e.g. interview } \\
\text { schedule, questions }\end{array}$ & $\sqrt{ }$ & $\sqrt{ }$ & $\sqrt{ }$ & $x$ & $\sqrt{ }$ & $\sqrt{ }$ & $\sqrt{ }$ \\
\hline & $\begin{array}{l}\text { Clear explanation of how data were collected/ methods are } \\
\text { explicit, justified }\end{array}$ & $\sqrt{ }$ & $\sqrt{ }$ & $\sqrt{ }$ & $\sqrt{ }$ & $\mathrm{x}$ & $\sqrt{ }$ & $\sqrt{ }$ \\
\hline & $\begin{array}{l}\text { Clear explanation of form of data, and modification during } \\
\text { study, and data handling }\end{array}$ & $\sqrt{ }$ & $\sqrt{ }$ & $\sqrt{ }$ & $\sqrt{ }$ & $\sqrt{ }$ & $\sqrt{ }$ & $x$ \\
\hline \multirow{3}{*}{ Analysis } & In-depth description of analysis process & $\sqrt{ }$ & $\sqrt{ }$ & $\mathrm{x}$ & $x$ & $x$ & $\sqrt{ }$ & $\mathrm{x}$ \\
\hline & Clear description of how categories/themes were derived & $\sqrt{ }$ & $\sqrt{ }$ & $\mathrm{x}$ & $x$ & $\mathrm{x}$ & $\mathrm{x}$ & $\mathrm{x}$ \\
\hline & $\begin{array}{l}\text { Clear description of how data were selected /how } \\
\text { contradictory data/ outliers were handled etc }\end{array}$ & $x$ & $\mathrm{x}$ & $x$ & $\mathrm{x}$ & $\mathrm{x}$ & $x$ & $\sqrt{ }$ \\
\hline \multirow{3}{*}{ Findings } & Sufficient explicit data presented to support findings & $\sqrt{ }$ & $\sqrt{ }$ & $\sqrt{ }$ & $\mathrm{x}$ & $\sqrt{ }$ & $\sqrt{ }$ & $\mathrm{x}$ \\
\hline & $\begin{array}{l}\text { Adequate discussion of evidence for and against researchers } \\
\text { arguments }\end{array}$ & $\sqrt{ }$ & $\sqrt{ }$ & $\sqrt{ }$ & $\mathrm{x}$ & $\sqrt{ }$ & $\sqrt{ }$ & $\mathrm{x}$ \\
\hline & Testing of robustness / credibility of findings & $\mathrm{x}$ & $\mathrm{x}$ & $\mathrm{x}$ & $\mathrm{x}$ & $x$ & $\sqrt{ }$ & $\mathrm{x}$ \\
\hline Researcher reflexivity & $\begin{array}{l}\text { Examination of own role, and potential for bias at all stages } \\
\text { e.g. formulation, collection, analysis }\end{array}$ & $x$ & $\mathrm{x}$ & $\bar{x}$ & $x$ & $\mathrm{x}$ & $\sqrt{ }$ & $x$ \\
\hline Generalisability & Can findings be applied to population of interest? & $\sqrt{ }$ & $\sqrt{ }$ & $x$ & $\sqrt{ }$ & $\sqrt{ }$ & $\sqrt{ }$ & $\sqrt{ }$ \\
\hline \multirow[t]{2}{*}{ Ethical issues } & $\begin{array}{l}\text { Research was adequately explained to participants, with } \\
\text { informed consent, and maintenance of confidentiality }\end{array}$ & $\sqrt{ }$ & $\sqrt{ }$ & $\sqrt{ }$ & $\sqrt{ }$ & $x$ & $\sqrt{ }$ & $x$ \\
\hline & SUMMARY OF QUALITY & $1++$ & $1++$ & $1-$ & $1-$ & $1+$ & $1+$ & $1-$ \\
\hline
\end{tabular}





\begin{tabular}{|c|c|c|c|c|c|c|c|}
\hline & $\begin{array}{l}\text { SUMMARY OF QUALI TY - QUALI TATI VE STUDI ES: } \\
\text { STAFF VI EWS }\end{array}$ & Dingwall & Lekan & Funderberg & Resnick & Remsberg & Johnson \\
\hline $\begin{array}{l}\text { Appropriate research } \\
\text { design }\end{array}$ & J ustification for design/method discussed/appropriate & $\sqrt{ }$ & $\sqrt{ }$ & $\sqrt{ }$ & $\sqrt{ }$ & $\sqrt{ }$ & $\sqrt{ }$ \\
\hline \multirow{3}{*}{ Sampling } & Clear explanation of how participants were selected & $\sqrt{ }$ & $\bar{x}$ & $\bar{V}$ & $\bar{V}$ & $\bar{V}$ & $\bar{V}$ \\
\hline & $\begin{array}{l}\text { Appropriateness of sample to provide knowledge sought } \\
\text { by study }\end{array}$ & $\sqrt{ }$ & $\sqrt{ }$ & $\sqrt{ }$ & $\sqrt{ }$ & $\sqrt{ }$ & $\sqrt{ }$ \\
\hline & Explanation of final sample and reasons for non-response & $\sqrt{ }$ & $\sqrt{ }$ & $\sqrt{ }$ & $\mathrm{x}$ & $\mathrm{x}$ & $\mathrm{x}$ \\
\hline \multirow[b]{3}{*}{ Data collection } & $\begin{array}{l}\text { Clear explanation of what data were collected e.g. } \\
\text { interview schedule, questions }\end{array}$ & $\sqrt{ }$ & $x$ & $\sqrt{ }$ & $\sqrt{ }$ & $\sqrt{ }$ & $\sqrt{ }$ \\
\hline & $\begin{array}{l}\text { Clear explanation of how data were collected/ methods } \\
\text { are explicit, justified }\end{array}$ & $\mathrm{V}$ & $\mathrm{x}$ & $\mathrm{V}$ & $\mathrm{V}$ & $\mathrm{x}$ & $\mathrm{V}$ \\
\hline & $\begin{array}{l}\text { Clear explanation of form of data, and modification during } \\
\text { study, and data handling }\end{array}$ & $\sqrt{ }$ & $\mathrm{x}$ & $\sqrt{ }$ & $\checkmark$ & $\sqrt{ }$ & $\sqrt{ }$ \\
\hline \multirow{3}{*}{ Analysis } & In-depth description of analysis process & $\mathrm{x}$ & $\mathrm{x}$ & $\mathrm{x}$ & $\sqrt{ }$ & $\sqrt{ }$ & $\mathrm{x}$ \\
\hline & Clear description of how categories/themes were derived & $\mathrm{x}$ & & $\mathrm{x}$ & $\sqrt{ }$ & & $\mathrm{x}$ \\
\hline & $\begin{array}{l}\text { Clear description of how data were selected / how } \\
\text { contradictory data/ outliers were handled } \\
\text { etc/completeness }\end{array}$ & $\sqrt{ }$ & $\mathrm{x}$ & $\sqrt{ }$ & $\mathrm{x}$ & $\mathrm{x}$ & $\mathrm{x}$ \\
\hline \multirow{3}{*}{ Findings } & $\begin{array}{l}\text { Sufficient explicit data presented to support findings/\% } \\
\text { response known }\end{array}$ & $\bar{v}$ & $\bar{x}$ & $\bar{V}$ & $\bar{V}$ & $\bar{x}$ & $\bar{V}$ \\
\hline & $\begin{array}{l}\text { Adequate discussion of evidence for and against } \\
\text { researchers arguments/impact of bias/subgroups }\end{array}$ & $\sqrt{ }$ & $\sqrt{ }$ & $\mathrm{x}$ & $\sqrt{ }$ & $\sqrt{ }$ & $\mathrm{v}$ \\
\hline & $\begin{array}{l}\text { Testing of robustness / credibility of findings / reports } \\
\text { numbers of events/outcomes }\end{array}$ & $x$ & $\sqrt{ }$ & $\sqrt{ }$ & $\sqrt{ }$ & $\sqrt{ }$ & $\mathrm{x}$ \\
\hline Researcher reflexivity & $\begin{array}{l}\text { Examination of own role, and potential for bias at all } \\
\text { stages e.g. formulation, collection, analysis }\end{array}$ & $\sqrt{ }$ & $\sqrt{V}$ & $\mathrm{x}$ & $\bar{v}$ & $\bar{v}$ & $\bar{x}$ \\
\hline Generalisability & Can findings be applied to population of interest? & $\sqrt{ }$ & $\sqrt{ }$ & $\mathrm{x}$ & $\sqrt{ }$ & $\sqrt{ }$ & $\mathrm{x}$ \\
\hline \multirow[t]{2}{*}{ Ethical issues } & $\begin{array}{l}\text { Research was adequately explained to participants, with } \\
\text { informed consent, and maintenance of confidentiality }\end{array}$ & $\sqrt{v}$ & $\sqrt{v}$ & $\sqrt{v}$ & $\sqrt{v}$ & $\mathrm{x}$ & $\sqrt{v}$ \\
\hline & SUMMARY OF QUALITY & $1+$ & $1-$ & $1+$ & $1++$ & $1-$ & $1-$ \\
\hline
\end{tabular}

